\title{
Calorie restriction and susceptibility to intact pathogens
}

\author{
Deborah M. Kristan
}

Received: 10 April 2008 / Accepted: 14 April 2008 / Published online: 27 May 2008

(C) American Aging Association 2008

\begin{abstract}
Long-term calorie restriction (CR) causes numerous physiological changes that ultimately increase mean and maximum lifespan of most species examined to date. One physiological change that occurs with $\mathrm{CR}$ is enhanced immune function, as tested using antigens and mitogens to stimulate an immune response. Fewer studies have used intact pathogen exposure to test whether the enhanced capacity of the immune response during CR actually decreases susceptibility of hosts to their pathogens. So far, studies using intact bacteria, virus, and helminth worm exposure indicate that, despite similar or enhanced immune system function, CR hosts are more susceptible to infection by intact pathogens than their fully fed counterparts. Long-term CR studies that examine susceptibility to a variety of parasite taxa will help determine if direct CR or CR mimetics will be beneficial to people living in pathogen-rich environments.
\end{abstract}

Keywords Calorie restriction - Immune response · Macroparasites · Microparasites · Susceptibility

\section{Abbreviations \\ AGEs Advanced glycosylation end-products \\ AL ad libitum \\ CR Calorie restriction}

D. M. Kristan $(\bowtie)$

Department of Biological Sciences,

California State University San Marcos,

333 S. Twin Oaks Valley Road,

San Marcos, CA 92096, USA

e-mail: dkristan@csusm.edu
IL Interleukin

LPS Lipopolysaccharide

ROS Reactive oxygen species

Th1 T helper cell type 1

Th2 T helper cell type 2

\section{Introduction}

Long-term calorie restriction (CR) causes many physiological changes that alter life-history traits such as growth, reproduction, and lifespan. Increased lifespan as a result of CR is of special interest to biogerontologists (see e.g., Weindruch and Walford 1988; Weindruch 1996; Masoro 2005; Masoro 2006), and the numerous confirmations of increased lifespan due to long-term CR have shaped new fields of research, such as the development of CR mimetics (Ingram et al. 2006; Chen and Guarente 2007; Lane et al. 2007) and the direct use of CR by people (Heilbronn et al. 2006; Das et al. 2007; Holloszy and Fontana 2007). Although the usefulness of CR or CR mimetics in humans remains controversial (Everitt and Le Couteur 2007; Speakman and Hambly 2007), if their effects on people are similar to those observed on laboratory animals, CR could increase human lifespan to a degree not seen since the advent of modern medicine and antibiotics in the early to mid1900s. An essential caveat to bear in mind, however, is that the laboratory environment used in most CR research is quite different from the typical human environment.

This paper is focused on one environmental difference, namely the occurrence of pathogens. CR studies are typically conducted in specific-pathogen-free envi- 
ronments or in clean conventional vivariums. These controlled conditions have been extremely beneficial for isolating the effects of $\mathrm{CR}$ on animal physiology and subsequent aging without the confounding effects of infectious disease. As a result, researchers have made tremendous progress toward understanding the proximate effects of $\mathrm{CR}$ on laboratory rodents, including changes in the immune system.

There is a long tradition among parasitologists to investigate the relationship between host diet and pathogen susceptibility (reviewed by Koski and Scott 2001; Field et al. 2002; Ritz and Gardner 2006). Diet composition is frequently manipulated to understand effects of particular nutrients, especially protein. Trace minerals, elements and vitamins also can affect parasite establishment and survival (Koski and Scott 2003; Rivera et al. 2003; Bourgeois et al. 2007), both when they are limited, and when they exceed normal levels. Few parasitological studies have separated the effects of CR from those of deficiency of micro- or macro-nutrients that are often imposed by using food restriction protocols (but see Shi et al. 1998; Koski et al. 1999). Because long-term CR studies ensure against macro- or micronutrient deficiency, these negative effects of nutrient deficiency on pathogen susceptibility are removed and the beneficial effects of $\mathrm{CR}$ on immune function in the presence of parasites can be examined.

It is well established that the typical decline in immune function with age is ameliorated by CR in laboratory rodents (Spaulding et al. 1997; Jolly et al. 1999; Pahlavani 2000, 2004), and more recently in longer-lived species, including dogs (Greeley et al. 2006) and non-human primates (Nikolich-Žugich and Messaoudi 2005; Messaoudi et al. 2006). These observations support the idea that CR may increase lifespan, at least partially, because age-associated disease is delayed or prevented altogether (e.g., Weindruch and Walford 1982). It follows that enhanced capacity for immune response during CR should not only prevent age-associated diseases, it should prevent or decrease the incidence of infectious disease at any age. A nontraditional, yet essential, experimental approach to test this idea is to measure the effects of CR on susceptibility to intact pathogens. This review will (1) briefly discuss the effects of CR duration on the dynamic physiological changes that occur between the initiation of $\mathrm{CR}$ and the long-term consequences of $\mathrm{CR}$; (2) compare traditional and non- traditional approaches to the study of $\mathrm{CR}$ and immune function; (3) summarize current knowledge regarding the relationship between long-term $\mathrm{CR}$ and immune responses of mice when tested with intact pathogens; (4) present some general methodological considerations for the use of intact pathogens in CR studies; (5) discuss benefits and drawbacks of using intact pathogens in long-term CR experiments; and (6) note how studies that use intact pathogens can contribute to understanding the possible benefits of $\mathrm{CR}$ and $\mathrm{CR}$ mimetics to human populations.

\section{Duration of calorie restriction}

The effects of $\mathrm{CR}$ on the immune response, and on many other physiological factors, will depend on the duration of CR. "Long-term CR" is a relative term, and its designation in chronological time necessarily varies with the lifespan of the organism being studied. While it may be tempting to set "long-term" to some percentage of maximum lifespan of the species, a designation of long-term CR should, if possible, also consider the time required to reach the new levels of physiological homeostasis that result from chronic CR. This review will focus on laboratory rodents, primarily mice (Mus musculus), because they are commonly used in CR studies that examine immune function. For laboratory mice subjected to $\mathrm{CR}$, body mass has generally stabilized after 3-4 weeks and, although it initially differs, by 6-8 weeks mass-specific metabolic rate is similar for CR and ad libitum-fed (AL) animals (Masoro 1998); at 24 weeks (but not at 12 weeks) there is increased production of the antioxidants catalase, superoxide dismutase, and glutathione peroxidase (Wu et al. 2003b). Based on such physiological changes, 20 weeks was the minimum duration of CR I considered as "long-term" for the purposes of evaluating literature for this review. Acute $\mathrm{CR}$ was defined to be up to 2 weeks and moderate $\mathrm{CR}$ was defined as 3-19 weeks. While these duration designations are somewhat arbitrary, they serve as a starting point to investigate variation in physiological and morphological changes that occur along the way to the final goal of long-term CR.

In order to realize the benefits of long-term CR, individuals must first survive the physiological changes caused by acute- and moderate-duration CR. In controlled laboratory environments, this may not be 
an issue for most individuals, but in natural and more variable environments any detrimental effects of shorter duration $\mathrm{CR}$ may become important. For example, as discussed in more detail below, the effects of $\mathrm{CR}$ on susceptibility of mice to pathogens will depend on whether CR duration is acute, moderate, or long-term. Therefore, in addition to measuring intact pathogen susceptibility after long-term CR, we also need to document the costs and benefits of shorter CR duration on immune function and pathogen susceptibility.

\section{CR and immune response: traditional approaches}

In many studies, changes in immune function with longterm $\mathrm{CR}$ are measured near the end of an experiment, typically after as long a period of $\mathrm{CR}$ as is feasible. A number of excellent reviews describe in detail the numerous changes in the immune system that occur with aging (e.g., Effros 2001; Gomez et al. 2005; Aw et al. 2007; Gruver et al. 2007), and how these age-associated changes are influenced by long-term CR (Pahlavani 2000, 2004). This information will not be reviewed here, except to note general methods used to study the relationship between $\mathrm{CR}$ and immune function.

Traditionally, the vast majority of tests of immune system function after long-term CR have been done using antigens or mitogens (reviewed in Pahlavani 2000). After in vivo exposure to an antigen (e.g., lipopolysaccharide, keyhole limpet hemocyanin, sheep red blood cells), circulating indicators of immune function in the blood, such as cytokine or antibody activity, can be measured. In addition, cells can be isolated for ex vivo studies to assess the capacity for the immune system to respond to stimulation. Often splenocyte or lymph-node proliferation is assessed by stimulation with mitogens (e.g., concanavalin A). Published studies nearly all show that $\mathrm{CR}$ attenuates the age-associated decline in the capacity of the immune system to respond to challenge (Pahlavani 2000). Effros et al. (1991) used similar immune function measures but examined mice that were immunized with intact virus via intraperitoneal injection. This study was unique because cells used in subsequent in vitro experiments were challenged with intact virus. Their results confirmed previous research using exclusively antigens or mitogens and showed that long-term CR was beneficial to the immune system.
Studies of immune system function in response to antigen and mitogen stimulation have yielded a wealth of information detailing changes in immune function with normal aging and after long-term CR. These data are especially valuable because individual components of the immune response can be isolated and thus well characterized. However, it is important not only to know the capacity for immune system function when stimulated with antigens and mitogens, but also how the immune system responds when the entire animal is exposed to whole, fully functioning pathogens acquired through an infectious route.

\section{CR and immune response: nontraditional approaches}

The effects of CR on host susceptibility may vary depending on the type or taxon of parasite. Parasites can be broadly classified as either micro- or macro-parasites. Microparasites are typically single-celled organisms that include viruses, bacteria and protozoans, but also can include multicellular species such as myxozoans (Anderson and May 1979; Morand et al. 2006). Macroparasites are typically large, multicellular metazoan parasites that include helminth worms and ectoparasitic arthropods (Anderson and May 1979; Morand et al. 2006). Within these broad categories of pathogens, different parasite species typically stimulate different components of the immune system. Microparasites tend to elicit a T-helper cell type 1 (Th1) immune response, whereas macroparasites tend to elicit a Th2 immune response, demonstrating that different types of helper $\mathrm{T}$ cells become active in response to different pathogens. Because CR also may affect T lymphocyte subsets differently (Miller 1997), it is important to test for CR effects on infections using pathogens that elicit Th1 responses and other pathogens that elicit $\mathrm{Th} 2$ responses. These two broad categories of pathogens also may respond differently to changes in host diet quality and quantity, hence investigations of relationships between $\mathrm{CR}$ and infections by numerous parasite taxa would be beneficial.

Thus far, most studies that have used intact pathogen inoculations to examine the effects of $\mathrm{CR}$ have used moderate $\mathrm{CR}$ durations ranging from 3 to 11 weeks (Table 1). Studies using bacteria have shown that moderate-duration $\mathrm{CR}$ protected against infection, whereas mice subjected to long-term $\mathrm{CR}$ 
died from infection, on average, before mice fed AL. Studies of viruses have shown either a beneficial or no effect of $\mathrm{CR}$ of moderate duration, but a detrimental effect after long-term CR. For nematode worms, acute and moderate infection durations revealed either no effect of $\mathrm{CR}$ or a detrimental effect of CR, and long-term CR increased susceptibility of mice to nematodes. The different conclusions among these studies indicates that it would be useful to study changes in immune function using $\mathrm{CR}$ of varying durations for each type of pathogen to determine the point at which susceptibility to infection may change.

\section{Current knowledge of long-term CR and pathogen susceptibility}

CR and susceptibility to microparasites

To the best of my knowledge, there are only two published reports of the effects of long-term CR on susceptibility to microparasites (Sun et al. 2001; Gardner 2005). In one experiment, Sun et al. (2001) ligated then punctured the intestinal ceca of mice to induce a bacterial infection that resulted in polymicrobial sepsis; in a second experiment, they measured the response of CR mice to lipopolysaccharide (LPS), a cell-wall component of Gram-negative bacteria. After LPS stimulation, macrophages from CR mice had a decreased capacity for phagocytosis and moderate levels of some Th1 cytokines [interleukin (IL)-6, IL-12]. Interestingly, after cecal ligation and puncture, CR mice showed extensive Th1 cytokine production (IL-6, tumor necrosis factor-alpha), which can contribute to pathology, and these CR mice died sooner from sepsis than AL mice (Sun et al. 2001). The different intensities of cytokine responses to LPS versus intact bacteria following cecal puncture emphasize the necessity of using intact pathogens to assess functional immune responses of CR animals.

The effects of long-term CR on susceptibility to viral exposure was tested with a primary intranasal inoculation of influenza virus into a mouse host (Gardner 2005). Gardner (2005) found that, although CR enhanced concanavalin-A-induced splenocyte proliferation in vitro, it did not increase natural killer cell activity in lungs compared to that in AL mice. Ultimately, old CR mice had higher virus titers and died sooner of influenza infection compared to young or old
AL mice. This raises an essential question about the apparently beneficial effects of CR: why should CR mice die sooner from viral infections than AL mice if their immune systems have a greater capacity to respond to viral challenge as measured by splenocyte proliferation? One possible explanation relevant to influenza virus may relate to energy needed to recover body mass that is typically lost during infection. Influenza infection caused weight loss for all mice during the first 4 days post-inoculation (Gardner 2005), after which both young and old AL animals either maintained or increased body mass, while CR animals continued to lose body mass after 4 days (Gardner 2005). Ritz and Gardner (2006) postulate that CR mice may not have the necessary reserves to meet the energetic demand associated with the immune response to a primary influenza infection. Mounting an immune response is energetically costly for small rodents, especially compared to the relatively low cost of maintaining but not using the immune system (Derting and Compton 2003). Energetic costs of immunity will likely vary among host-pathogen associations, but may be especially pertinent for studies of CR where energy reserves are diminished or significantly depleted. Moreover, pathogens that reside in the intestine can directly alter nutrient absorption and subsequent availability which may result in unique interactions with $\mathrm{CR}$ compared to other pathogens residing outside of the intestinal tract. Taken together, results from microparasites question whether CR will promote fitness in natural environments where infectious pathogens are present.

\section{CR and susceptibility to macroparasites}

To date, I am aware of only one study that has examined the effects of long-term CR on susceptibility of mice to a macroparasite infection. Work in my lab showed that after 6.7 months of $\mathrm{CR}$, mice were more susceptible than AL mice to a primary exposure of Heligmosomoides bakeri, a nematode worm that resides in the mouse small intestine (Kristan 2007). The greater number of adult worms found in CR compared to $\mathrm{AL}$ mice was likely due to enhanced adult worm survival, since larval establishment was similar in another experiment comparing $\mathrm{AL}$ and $\mathrm{CR}$ mice (D.M. Kristan and W. Acosta, unpublished data).

Further research indicated that CR likely does not protect against establishment of larvae in a secondary 


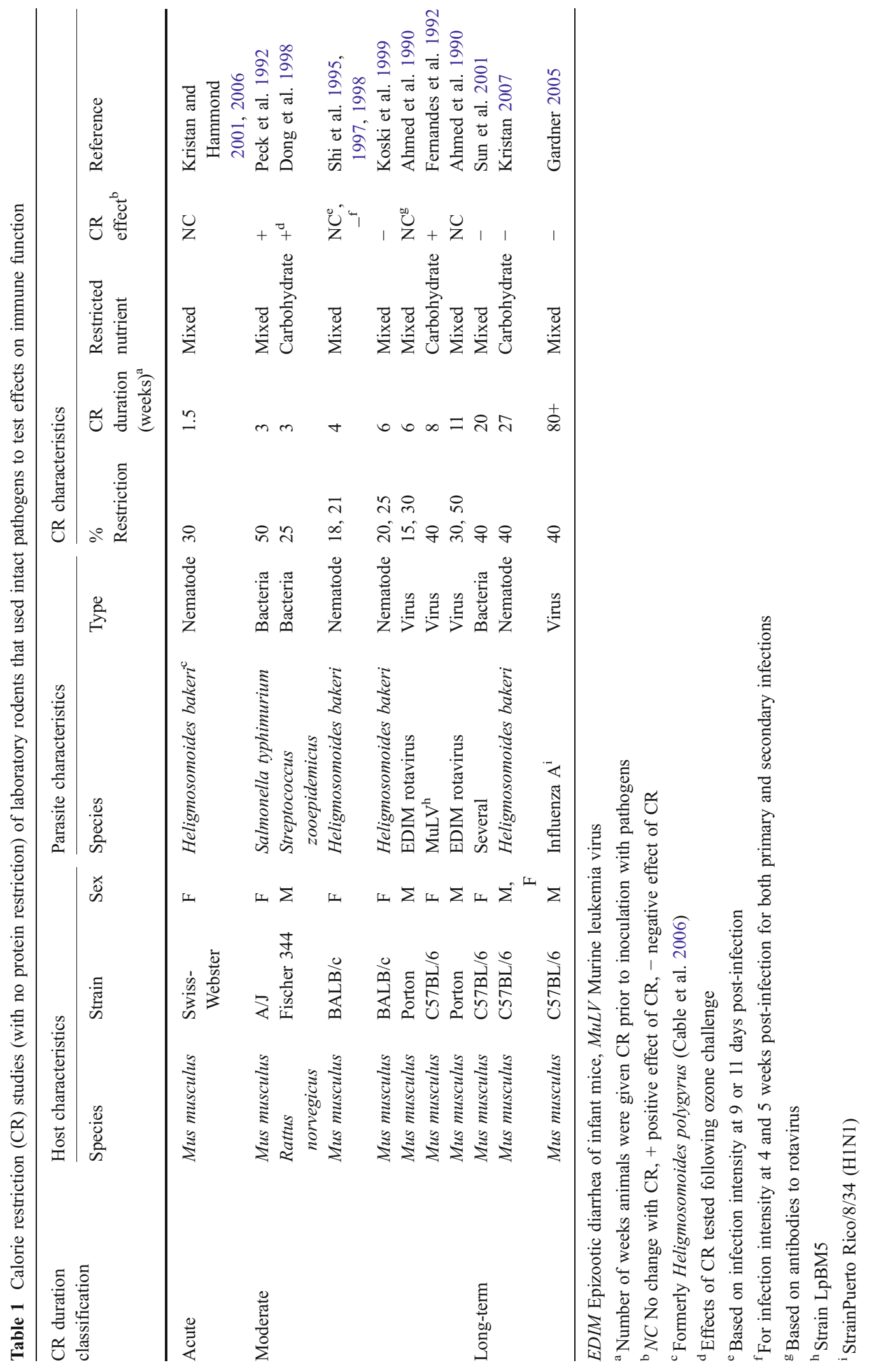


exposure with $H$. bakeri. During secondary infections, CR mice had similar numbers of adult worms to those found in AL mice at 16 days after secondary inoculation, but retained more worms than $\mathrm{AL}$ mice at 24 days post-secondary inoculation (W. Acosta and D.M. Kristan, unpublished data), indicating that CR slows parasite clearance by the host and thereby may increase the long-term cost of infection to the host.

Many parasitic worms do not kill their hosts, but rather establish chronic, sometimes lifelong, infections. For pathogens that establish long-term infections in hosts also subjected to lifelong CR, several measures of the host-parasite relationship deserve systematic evaluation, including effects of host CR on (1) clearance rate and duration of infection; (2) adaptive immune response and susceptibility to subsequent infections; and (3) pathogen reproduction and effects on transmission to conspecifics of the same population. Parasitic worms also often increase host morbidity (Stephenson et al. 2000; Hayes et al. 2004) and alter host susceptibility to other infectious pathogens (Page et al. 2006). The effect of CR on heterologous infection has yet to be investigated but is a topic that would provide valuable data directly relevant to human populations exposed to a diverse range of pathogen types.

\section{General considerations when using intact pathogens}

As noted above, only a few studies have exposed rodents to intact pathogens following long-term CR (Table 1). As more experiments like these are undertaken, there are several factors to consider, such as the choice of host and pathogen and several aspects of how the pathogen will be administered. Because so much is known about the effects of CR on laboratory rodents, they would initially be a useful host to use for research with intact pathogens. Of course, there is variation in response to $\mathrm{CR}$ even among inbred mouse strains (Turturro et al. 1999; Brochmann et al. 2003; Rikke et al. 2003, 2006), as well as between males and females (Wu et al. 2003a; Shi et al. 2007). Mouse strain and sex also influence susceptibility to pathogens (Zuk and McKean 1996; Morales-Montor et al. 2004; Behnke et al. 2006), and these effects are pathogen-specific. Therefore, if a laboratory mouse is selected as an experimental host, mouse strain and sex must be considered from both a CR and pathogen susceptibility perspective.
Once the host has been selected, there are a number of broad considerations to address regarding pathogen exposure. A first and fundamental consideration is which type of pathogen to use. Microparasites typically multiply within the host, induce immunity to reinfection, and have short lifespans relative to the host. Macroparasites, in contrast, typically do not multiply within the host, have hosts that are frequently susceptible to repeated infections, and produce persistent infections that can last for a long portion of the host's lifespan (Anderson and May 1979). Species within these broad categories can be chosen based on characteristics that elicit the desired immune system responses.

For both microparasites and macroparasites, there may be laboratory strains of pathogens as well as wild pathogens available. The use of wild pathogens is appealing because their genetic heterogeneity will mimic that of human pathogens, which contribute to uneven virulence among individuals. However, as we begin this new avenue of research it may be initially advantageous to use laboratory pathogen strains because many laboratory strains are well characterized regarding their genetics, life cycle, pathogenicity, and host immune responses. The availability of this baseline information provides a solid experimental background to examine the combined effects of long-term $\mathrm{CR}$ and parasite infection.

A second consideration is the route of inoculation. For example, when intact influenza virus is administered with an intraperitoneal injection, it acts as a vaccine (Effros et al. 1991), whereas when the same virus is given intranasally, it produces a primary infection in the lung (Gardner 2005). For some other pathogens, it is possible for parasites to become established in the host even if they are administered experimentally in ways that differ from the natural exposure route. For example, Toxoplasma gondii is a protozoan parasite that is acquired orally by definitive and intermediate hosts in nature, but it will readily establish in mice via intraperitoneal or subcutaneous injections in the laboratory (depending on Toxoplasma strain, Dubey et al. 1999), and, in people, via contaminated organs during transplant (Hill and Dubey 2002). Even though Toxoplasma will successfully establish through many routes, hosts show differences in their responses to the pathogen depending on the route of exposure (Tedesco et al. 2005). For experiments designed to examine the role of longterm CR on pathogen susceptibility, natural routes of 
inoculation may best elucidate how people using CR or $\mathrm{CR}$ mimetics may respond to the pathogens they will encounter.

A third consideration is pathogen dose. Depending on the pathogen taxa used, the suitable number of eggs or larvae for macroparasites, or hemagglutinin assay units (HAU) or plaque-forming units (PFU) for viruses, for example, would need to be determined. Whether the researcher wished to induce clinical symptoms of disease or produce a subclinical infection would dictate appropriate pathogen dose. These doses would necessarily be chosen initially based on responses of AL hosts for which data are currently available. It is possible, however, that pathogen doses that elicit one type of response by an AL host may elicit a different response when given to a CR host, so that doses would need to be adjusted accordingly.

A fourth consideration is the frequency of exposure. So far, published studies have used only primary infections to examine the effects of long-term CR on host susceptibility. To investigate all aspects of the host immune response, studies using secondary and repeated exposures of the same pathogen-and, eventually, combinations of different types of pathogens - are needed. These kinds of more realistic experiments will be important, since people routinely experience primary, secondary and repeated exposures to multiple pathogens simultaneously.

\section{Benefits of using intact pathogens}

The use of intact pathogens to test CR effects on immune responses has several benefits. First, if CR or CR mimetics are to be used by people, it will be important to understand $\mathrm{CR}$ effects on host immune response in an experimental setting that most closely approximates the human environment. People encounter all types of pathogens, ranging from microparasites to macroparasites, and must respond to the entire, intact pathogen. An understanding of responses to intact pathogens during $\mathrm{CR}$, therefore, will enhance our ability to predict the effects of CR on people.

Second, the published studies that examined longterm CR and susceptibility to intact pathogens show that increased susceptibility at the whole-animal level was not predicted by molecular and cellular responses as traditionally measured. Therefore, it appears that under- standing molecular and cellular responses to antigens and mitogens are not sufficient to predict whole-animal responses to intact pathogens, at least in the context of long-term CR. Using intact pathogens should strengthen our ability to make robust predictions about CR effects on host susceptibility.

Third, experimental exposure to intact pathogens would allow researchers to expand the range of variables that can be measured or manipulated in the host, and open new avenues of research. For example, some parasites produce immunomodulatory factors to promote chronic infection (Dzik 2006; Rzepecka et al. 2006). If host CR allows for enhanced production or function of these parasite-derived factors, parasites may be able to survive better in CR hosts. It is also well known that host hormones influence parasite establishment and reproduction (Escobedo 2005). If CR-induced changes in host hormone production alter parasite establishment or survival, they also could affect host susceptibility. Another possibility is measuring reactive oxygen species (ROS) that hosts use in an oxidative burst to kill micro- (Miller and Britigan 1997) and macro-parasites (Bender et al. 2005). It is well known that CR decreases production of ROS during normal metabolism (Lopez-Torres et al. 2002; Ward et al. 2005); this is considered to be beneficial because CR animals incur less oxidative damage than AL animals (Merry 2002). However, if CR also decreases the ability to produce ROS needed to kill pathogens, CR could become a liability. An examination of these variables and other phenomena associated with intact pathogen infection would provide a broader understanding of the interaction between $\mathrm{CR}$ and pathogen susceptibility.

Fourth, when a host encounters a pathogen, not only does the immune system respond to the protein coat or other isolated components of the pathogen, the host also can incur physical damage from the pathogen. For example, parasitic worms often migrate through the host, sometimes through many organs and layers of tissue, causing mechanical damage before reaching the final destination. Some pathogens (e.g., Toxoplasma gondii) enclose themselves in cysts that occupy space in a variety of organs, where they can persist for the lifetime of the host. Other pathogens actively consume host tissue as food (Bansemir and Sukhdeo 1994). Recognizing that the pathogen is an active participant in the host-pathogen relationship will broaden our understanding of whether CR actually enhances pathogen 
resistance. Including a second living organism adds complexity to experimental models, however, and with this complexity may come drawbacks.

\section{Drawbacks of using intact pathogens}

Parasites may directly or indirectly influence hosts in ways completely unrelated to immune function. For example, parasite infection can alter host resting metabolism and body composition (Kristan and Hammond 2001), pain tolerance (Kavaliers and Colwell 1993), learning (Kavaliers and Colwell 1995), and function of the tissue where the worms reside (Kristan and Hammond 2001). CR alone also may alter some of the same parameters in the absence of intact pathogen infection (Kristan and Hammond 2006). It would be informative to determine if $\mathrm{CR}$ and pathogens produce additive, synergistic, or opposing effects in these various aspects of host biology when both occur simultaneously, and if any of these effects influence effectiveness of immune responses.

Another drawback - perhaps most notably for intestinal pathogens - is the potential of pathogens to both directly and indirectly influence energy availability, the very currency being altered during CR. Changes in nutrient absorption or passage rate of ingesta through the intestine (e.g., via alterations in mucosal tissue or the enteric nervous system) can influence the number of calories available to the animal. In our laboratory, longterm CR mice had slightly but significantly lower digestive efficiency than AL mice (W. Acosta and D.M. Kristan, unpublished data). If digestive efficiency changes with pathogen infection and $\mathrm{CR}$, then $\mathrm{CR}$ individuals may have fewer or more calories available than intended by the experimental design.

Last, depending on the pathogen, it may be difficult to maintain and control infection intensity within a host. Some pathogens, especially microparasites, readily replicate within their host; therefore, the initial experimental dose can increase to uncontrolled infection levels. Directly replicating parasites would be more difficult to study compared to parasites that have a freeliving stage or indirect life cycle, where infection of the final mammalian host can be readily experimentally controlled. Such potential drawbacks of using intact pathogens will vary depending on the pathogen taxa used; therefore, unique challenges will occur each time we try to examine the role of intact pathogen exposure after long-term host CR.

\section{Relevance of intact pathogens to CR and CR mimetics in human populations}

There are numerous differences between the laboratories where we conduct research and the environments where people live. If we hope ultimately to make CR research clinically applicable, it will be useful to mimic the human environment whenever possible. One way to accomplish this is to use intact pathogen exposure during tests of immune function in CR studies. Even if research concludes that $\mathrm{CR}$ increases susceptibility to some pathogens, CR or CR mimetics may still be useful to people. Such a finding could indicate that additional therapeutic support may be necessary for people who choose to use CR as a way to promote healthy living with the hope of extending lifespan. Based on the limited empirical evidence to date, the predictions that researchers make regarding the effects of $\mathrm{CR}$ on pathogen susceptibility may differ dramatically depending on whether traditional measures of immune response are exclusively used (e.g., antigen and mitogen stimulation followed by in vitro assays), or if these measures are supplemented by experiments that include exposure with intact pathogens.

Acknowledgments This paper benefitted greatly by comments from Donna Holmes, Jim Harper and an anonymous reviewer. Wendy Acosta contributed to data collection of unpublished results, which were funded by California State University San Marcos.

\section{References}

Ahmed F, Jones DB, Jackson AA (1990) Effect of undernutrition on the immune response to rotavirus infection in mice. Ann Nutr Metab 34:21-31

Anderson RM, May RM (1979) Population biology of infectious diseases: part I. Nature 280:361-367

Aw D, Silva AB, Palmer DB (2007) Immunosenescence: emerging challenges for an ageing population. Immunology 120:435-46

Bansemir AD, Sukhdeo MVK (1994) The food resource of adult Heligmosomoides polygyrus in the small intestine. J Parasitol 80:24-28

Behnke JM, Mugambi JM, Clifford S, Iraqi FA, Baker RL, Gibson JP, Wakelin D (2006) Genetic variation in resistance to repeated infections with Heligmosomoides 
polygyrus bakeri, in inbred mouse strains selected for the mouse genome project. Parasite Immunol 28:85-94

Bender RC, Broderick EJ, Goodall CP, Bayne CJ (2005) Respiratory burst of Biomphalaria glabrata hemocytes: Schistosoma mansoni-resistant snails produce more extracellular $\mathrm{H}_{2} \mathrm{O}_{2}$ than susceptible snails. J Parasitol 91:275279

Bourgeois AC, Scott ME, Sabally K, Koski KG (2007) Low dietary boron reduces parasite (Nematoda) survival and alters cytokine profiles but the infection modifies liver minerals in mice. J Nutr 137:2080-2086

Brochmann EJ, Duarte ME, Zaidi HA, Murray SS (2003) Effects of dietary restriction on total body, femoral, and vertebral bone in SENCAR, C57BL/6, and DBA/2 mice. Metabolism 52:1265-1273

Cable J, Harris PD, Lewis JW, Behnke JM (2006) Molecular evidence that Heligmosomoides polygyrus from laboratory mice and wood mice are separate species. Parasitology 133:111-122

Chen D, Guarente L (2007) SIR2: a potential target for calorie restriction mimetics. Trends Mol Med 13:64-71

Das SK, Gilhooly CH, Golden JK, Pittas AG, Fuss PJ, Cheatham RA, Tyler S, Tsay M, McCrory MA, Lichtenstein AH, Dallal GE, Dutta C, Bhapkar MV, Delany JP, Saltzman E, Roberts SB (2007) Long-term effects of 2 energyrestricted diets differing in glycemic load on dietary adherence, body composition, and metabolism in CALERIE: a 1-y randomized controlled trial. Am J Clin Nutr 85:10231030

Derting TL, Compton S (2003) Immune response, not immune maintenance, is energetically costly in wild white-footed mice (Peromyscus leucopus). Physiol Biochem Zool 76:744-752

Dong W, Selgrade MK, Gilmour MI, Lange RW, Park P, Luster MI, Kari FW (1998) Altered alveolar macrophage function in calorie-restricted rats. Am J Respir Cell Mol Biol 19:462-469

Dubey JP, Shen SK, Kwok OC, Frenkel JK (1999) Infection and immunity with the RH strain of Toxoplasma gondii in rats and mice. J Parasitol 85:657-662

Dzik JM (2006) Molecules released by helminth parasites involved in host colonization. Acta Biochim Pol 53:33-64

Effros RB (2001) Immune system activity. In: Masoro EJ, Austad SN (eds) Handbook of the biology of aging. Academic, San Diego, pp 324-350

Effros RB, Walford RL, Weindruch R, Mitcheltree C (1991) Influences of dietary restriction in immunity to influenza in aged mice. J Gerontol Biol Sci 46:B142-B147

Escobedo G, Roberts CW, Carrero JC, Morales-Montor J (2005) Parasite regulation by host hormones: an old mechanism of host exploitation? Trends Parasitol 21:588-593

Everitt AV, Le Couteur DG (2007) Life extension by calorie restriction in humans. Ann N Y Acad Sci 1114:428-33

Fernandes G, Tomar V, Mohan N, Venkatraman JT (1992) Potential of diet therapy on murine AIDS. J Nutr 122:716722

Field CJ, Johnson IR, Schley PD (2002) Nutrients and their role in host resistance to infection. J Leukoc Biol 71:16-32

Gardner EM (2005) Caloric restriction decreases survival of aged mice in response to primary influenza infection. $\mathrm{J}$ Gerontol Biol Sci 60A:688-694
Gomez CR, Boehmer ED, Kovacs EJ (2005) The aging innate immune system. Curr Opin Immunol 17:457-62

Greeley EH, Spitznagel E, Lawler DF, Kealy RD, Segre M (2006) Modulation of canine immunosenescence by lifelong caloric restriction. Vet Immunol Immunopathol 111:287-99

Gruver AL, Hudson LL, Sempowski GD (2007) Immunosenescence of ageing. J Pathol 211:144-156

Hayes KS, Bancroft AJ, Grencis RK (2004) Immune-mediated regulation of chronic intestinal nematode infection. Immunol Rev 201:75-88

Heilbronn LK, de Jonge L, Frisard MI, DeLany JP, LarsonMeyer DE, Rood J, Nguyen T, Martin CK, Volaufova J, Most MM, Greenway FL, Smith SR, Deutsch WA, Williamson DA, Ravussin E (2006) Effect of 6-month calorie restriction on biomarkers of longevity, metabolic adaptation, and oxidative stress in overweight individuals: a randomized controlled trial. JAMA 295:1539-1548

Hill D, Dubey JP (2002) Toxoplasma gondii: transmission, diagnosis and prevention. Clin Microbiol Infect 8:634-640

Holloszy JO, Fontana L (2007) Caloric restriction in humans. Exp Gerontol 42:709-712

Ingram DK, Zhu M, Mamczarz J, Zou S, Lane MA, Roth GS, deCabo R (2006) Calorie restriction mimetics: an emerging research field. Aging Cell 5:97-108

Jolly CA, Fernandez R, Muthukumar AR, Fernandes G (1999) Calorie restriction modulates Th-1 and Th-2 cytokineinduced immunoglobulin secretion in young and old C57BL/6 cultured submandibular glands. Aging (Milano) 11:383-389

Kavaliers M, Colwell DD (1993) Multiple opioid system involvement in the mediation of parasitic-infection induced analgesia. Brain Res 623:316-320

Kavaliers M, Colwell DD (1995) Reduced spatial learning in mice infected with the nematode, Heligmosomoides polygyrus. Parasitology 110:591-597

Koski KG, Scott ME (2001) Gastrointestinal nematodes, nutrition and immunity: breaking the negative spiral. Annu Rev Nutr 21:297-321

Koski KG, Scott ME (2003) Gastrointestinal nematodes, trace elements, and immunity. J Trace Elem Exp Med 16:237251

Koski KG, Su Z, Scott ME (1999) Energy deficits suppress both systemic and gut immunity during infection. Biochem Biophys Res Commun 264:796-801

Kristan DM (2007) Chronic calorie restriction increases susceptibility of laboratory mice (Mus musculus) to a primary intestinal parasite infection. Aging Cell 6:817-825

Kristan DM, Hammond KA (2001) Parasite infection and caloric restriction induce physiological and morphological plasticity. Am J Physiol 281:R502-R510

Kristan DM, Hammond KA (2006) Effects of three simultaneous demands on glucose transport, resting metabolism and morphology of laboratory mice. J Comp Physiol [B] 176:139-151

Lane MA, Roth GS, Ingram DK (2007) Caloric restriction mimetics: a novel approach for biogerontology. Methods Mol Biol 371:143-149

Lopez-Torres M, Gredilla R, Sanz A, Barja G (2002) Influence of aging and long-term caloric restriction on oxygen 
radical generation and oxidative DNA damage in rat liver mitochondria. Free Radic Biol Med 32:882-889

Masoro EJ (1998) Influence of caloric intake on aging and on the response to stressors. J Toxicol Environ Health 1:243-257

Masoro EJ (2005) Overview of caloric restriction and ageing. Mech Ageing Dev 126:913-922

Masoro EJ (2006) Caloric restriction and aging: controversial issues. J Gerontol: Biol Sci 61A:14-19

Merry BJ (2002) Molecular mechanisms linking calorie restriction and longevity. Int J Biochem Cell Biol 34:1340-1354

Messaoudi I, Warner J, Fischer M, Park B, Hill B, Mattison J, Lane MA, Roth GS, Ingram DK, Picker LJ, Douek DC, Mori M, Nikolich-Zugich J (2006) Delay of T cell senescence by caloric restriction in aged long-lived nonhuman primates. Proc Natl Acad Sci USA 103: 19448-19453

Miller RA (1997) Age-related changes in T cell surface markers: a longitudinal analysis in genetically heterogeneous mice. Mech Ageing Dev 96:181-196

Miller RA, Britigan BE (1997) Role of oxidants in microbial pathophysiology. Clin Microbiol Rev 10:1-18

Morales-Montor J, Chavarria A, De Leon MA, Del Castillo LI, Escobedo EG, Sanchez EN, Vargas JA, Hernandez-Flores M, Romo-Gonzalez T, Larralde C (2004) Host gender in parasitic infections of mammals: an evaluation of the female host supremacy paradigm. J Parasitol 90:531-546

Morand S, Krasnov BR, Poulin R, Degen AA (2006) Micromammals and macroparasites: who is who and how do they interact? In: Morand S, Krasnov BR, Poulin R (eds) Micromammals and macroparasites: from evolutionary ecology to management. Springer, Tokyo, pp 3-9

Nikolich-Žugich J, Messaoudi I (2005) Mice and flies and monkeys too: caloric restriction rejuvenates the aging immune system of non-human primates. Exp Gerontol 40:884-893

Page KR, Scott AL, Manabe YC (2006) The expanding realm of heterologous immunity: friend or foe? Cell Microbiol 8:185-196

Pahlavani MA (2000) Caloric restriction and immunosenescence: a current perspective. Front Biosci 5:d580-d587

Pahlavani MA (2004) Influence of caloric restriction on aging immune system. J Nutr Health Aging 8:38-47

Peck MD, Babcock GF, Alexander JW (1992) The role of protein and calorie restriction in outcome from Salmonella infection in mice. J Parenter Enteral Nutr 16:561-565

Rikke BA, Yerg JE, Battaglia ME, Nagy TR, Allison DB, Johnson TE (2003) Strain variation in the response of body temperature to dietary restriction. Mech Ageing Dev 124:663-678

Rikke BA, Battaglia ME, Allison DB, Johnson TE (2006) Murine weight loss exhibits significant genetic variation during dietary restriction. Physiol Genomics 27:122-130

Ritz BW, Gardner EM (2006) Malnutrition and energy restriction differentially affect viral immunity. J Nutr 136:1141-1144

Rivera MT, De Souza AP, Araujo-Jorge TC, De Castro SL, Vanderpas J (2003) Trace elements, innate immune response and parasites. Clin Chem Lab Med 41:1020-1025

Rzepecka J, Lucius R, Doligalska M, Beck S, Rausch S, Hartmann S (2006) Screening for immunomodulatory proteins of the intestinal parasitic nematode Heligmosomoides polygyrus. Parasite Immunol 28:463-472
Shi HN, Scott ME, Koski KG, Boulay M, Stevenson MM (1995) Energy restriction and severe zinc deficiency influence growth, survival and reproduction of Heligmosomoides polygyrus (Nematoda) during primary and challenge infections in mice. Parasitol 110:599-609

Shi HN, Koski KG, Stevenson MM, Scott ME (1997) Zinc deficiency and energy restriction modify immune resposes in mice during both primary and challenge infection with Heligmosomoides (Nematoda). Parasite Immunol 19:363373

Shi HN, Scott ME, Stevenson MM, Koski KG (1998) Energy restriction and zinc deficiency impair the functions of murine $\mathrm{T}$ cells and antigen presenting cells during gastrointestinal nematode infection. J Nutr 128:20-27

Shi H, Strader AD, Woods SC, Seeley RJ (2007) Sexually dimorphic responses to fat loss after caloric restriction or surgical lipectomy. Am J Physiol Endocrinol Metab 293: E316-E326

Spaulding CC, Walford RL, Effros RB (1997) Calorie restriction inhibits the age-related dysregulation of the cytokines TNF-alpha and IL-6 in C3B10RF1 mice. Mech Ageing Dev 93:87-94

Speakman JR, Hambly C (2007) Starving for life: what animal studies can and cannot tell us about the use of caloric restriction to prolong human lifespan. J Nutr 137:10781086

Stephenson LS, Latham MC, Ottesen EA (2000) Malnutrition and parasitic helminth infections. Parasitol 121(Suppl):S23-S38

Sun D, Muthukumar AR, Lawrence RA, Fernandes G (2001) Effects of calorie restriction on polymicrobial peritonitis induced by cecum ligation and puncture in young C57BL/ 6 mice. Clin Diag Lab Immunol 8:1003-1011

Tedesco RC, Smith RL, Corte-Real S, Calabrese KS (2005) Ocular toxoplasmosis in mice: comparison of two routes of infection. Parasitol 131:303-307

Turturro A, Witt WW, Lewis S, Hass BS, Lipman RD, Hart RW (1999) Growth curves and survival characteristics of the animals used in the biomarkers of aging program. J Gerontol Biol Sci 54A:B492-B501

Ward WF, Qu W, Van Remmen H, Zackert WE, Roberts LJ, Richardson A (2005) Effects of age and caloric restriction on lipid peroxidation: measurement of oxidative stress by F2-isoprostane levels. J Gerontol Biol Sci 60A:847-851

Weindruch R (1996) The retardation of aging by caloric restriction: studies in rodents and primates. Toxicol Pathol 24:742-745

Weindruch R, Walford RL (1982) Dietary restriction in mice beginning at 1 year of age: effect on life-span and spontaneous cancer incidence. Science 215:1415-1418

Weindruch R, Walford RL (1988) The retardation of aging and disease by dietary restriction. Thomas, Springfield

Wu A, Sun X, Liu Y (2003a) Effects of caloric restriction on cognition and behavior in developing mice. Neurosci Lett 339:166-168

Wu A, Sun X, Wan F, Liu Y (2003b) Modulations by dietary restriction on antioxidant enzymes and lipid peroxidation in developing mice. J Appl Physiol 94:947-952

Zuk M, McKean KA (1996) Sex differences in parasite infections: patterns and processes. Int J Parasitol 26:1009-1023 